comparable with the period before 1895. Secondly, the paths of Atlantic depressions moved northward as the warmest epoch of this century was approached, and are now reversing southward, giving eirculation patterns more analogous to those in the nineteenth century. These investigations also promise to assist the experiments in long-range weather forecasting.

The remainder of the report consists of a brief summary of the work of each Branch, notes on the weather of 1963, a large number of statistics relating to the Services Directorate, and details of international commitments undertaken by members of the Office.

By its very nature the report can only deal with the work actually carried out by the Meteorological Office during the year. Any review, however, must be expected to comment not only on what has been done but also on what has been left undone, or at least unsaid. There is, for example, no indication that radar is being used operationally in any way by the Office. Radar is an instrument with the ability to detect precipitation, and although the interpretation is not easy, it ce ${ }^{\circ}$ provide both qualitative and quantitative information. rhus, radar has been used in the United States to estimate areal rainfall and hence to predict river-levels in many drainage basins whenever there is a flood risk, with consistently good results.

Here, however, the Meteorological Office is only considering the problem of river flood prediction ly constructing maps of estimated soil water deficit. While the possibility of using radar observations of precipitation distribution for short-period forecasting may not be established, surely any forecast for a few hours ahead would be assisted by patterns of the actual rain areas from hour to hour, which could be simply provided by a few correctly sited high-powered $10-\mathrm{cm}$ radars.

A more fundamental criticism can perhaps also be made. During recent years the Meteorological Office has brought itself closer to the public by the provision of weather information centres in four big cities and by maintaining contact with research and advisory workers in agriculture. There is, however, no evidence in this report that the Office is making any strong attempt to explore its further potential for the provision of services to the community. While the Research Directorate may justifiably exist purely to advance our knowledge of meteorology, any advances should be used to enable new, better or more reliable information to be given to those who require it, or who, if shown, might find it to be applicable. Yet if the significance of any new facilities, or even existing ones, is not impressed on the public, it cannot be expected to use the services of the Office correctly or fully. It may be, as the Director-General mentions, that the resources of the Office are being stretched to meet the large and only partially satisfied demands for information about weather and climate. Some redeployment may thus be called for within the Office, and one may even wonder whether the community would be better served by a meteorological service which is not a State monopoly, as is the case in some other parts of the world. J. R. Probert-Jones

\title{
THRIPLOW MEADOWS MANAGEMENT EXPERIMENT
}

$\mathrm{W}$ ET meadows, which were once used for rough grazing or mowing, have been disappearing in recent years at an alarming rate from many English counties. Modern farming practice has no place for such fields. Yet, in the past, they have carried a rich flora and fauna, and without them the English countryside would be gravely impoverished for the naturalist. Among the plants especially associated with wet meadows, the marsh orchids (Dactylorchis spp.) are particularly striking, often occurring in large numbers. One such population is well known to Cambridgeshire botanists around a stream near Thriplow on the estate of Lord Walston of Newton Hall. Here, in favourable seasons, thousands of handsome flowering spikes, mainly Dactylorchis praetermissa, can be seen in the roughly-grazed meadows.

In 1961 Lord Walston leased a small meadow within the orchid area for seven years to the Cambridgeshire and Isle of Ely Naturalists' Trust. 'This body successfully applied to the Nature Conservancy Board for a grant of $£ 250$ over five years to enable it to carry out a simple experiment in management of the meadow. The aim of the experiment was to determine the conditions of mowing or grazing under which the orchid populations were maintained or extended, so that it would be possible to recommend management procedure in cases where the Trust might have opportunities of protecting such communities. The work is described by G. Crompton and S. M. Walters in the 1964 Handbook* of the Society for the Promotion of Nature Reserves.

Until ten years ago, the meadow had been regularly grazed by cows. After this, cattle were grazed for six weeks at the end of each year, and for the past two years there was no grazing at all. With this diminution of grazing, Carex acutiformis increased considerably.

It was decided that, for experimental purposes, the meadow should be divided into four approximately equal

* Society for the Promotion of Nature Reserves. Handbook 1964: Forty-Seventh Annual Report, year ending 31st March, 1964. Pp. $58+$ plates. (London: The Society for the Promotion of Nature Reserves, British areas: Strip 1 to be grazed by horses, Strip 2 to be cut annually, Strip 3 to be the control, and Strip 4 to be grazed by cows. During the summer, and before the strips were cut, a rough sketch plin of the dominant vegetation was made. There are twel-re wet hollows in the meadow and their position was noted; a list has been made for each hollow of the interesting and dominant plants present.

By the end of the 1963 season the five-year experiment was at a half-way stage. Modifications to the original plan of grazing Strip 1 with horses and Strip 4 with cows were necessitated by practical difficulties. Records were prepared of the orchid population at the end of June each year by a volunteer party which counted the flowering spikes on each strip. The results are summarized as follows:

\begin{tabular}{crcr} 
Strip & 1961 & 1962 & 1963 \\
\hline 1 & 1,047 & 1,516 & 2,049 \\
2 & $486^{*}$ & 409 & 658 \\
3 & $693^{*}$ & Not counted & 498 \\
4 & c. $250^{*}$ & 716 & 1,281
\end{tabular}

* Probably underestimated because these strips were counted late--July

The figures, although incomplete, are revealing. In Strip 1 the initially high orchid population had almost doubled by 1963; in Strip 4 there was a significant increase. Rough grazing, whether by horses or cattle, was favourable to the orchid population-or at least to their free flowering. There is some evidence that the flower-spikes are avoided by the grazing animals, presumably because they are unpalatable. Cutting in August (Strip 2) did not diminish the flowering orchids, though there was no significant increase. It is only in the uncut and ungrazed control (Strip 3) that a decrease in flowering was evident. This is not surprising: over more than half the area of Strip 2 there is now a rank growth of $C$. acutiformis, with which few other species can effectively 
compete. The Carex is rapidly enlarging its area: at one point the boundary has moved forward $2.5 \mathrm{~m}$.

In addition to the orchid counts, a variety of other records are being kept. Variation in water-level has been recorded at a hole in Strip 3 showing a fairly regular pattern of high levels approximately from December to April or May, dropping rapidly in June. Permanent quadrats have been recorded against the dividing line between Strip 1 and Strip 2, and between Strip 3 and Strip 4. There is also a permanent quadrat in a low-lying area in Strip 3, where the rare sedge, Blysmus compressus, grows, and the boundary of $C$. acutiformis has been measured. In the past, where $C$. acutiformis is now dominant, Blysmus has disappeared and with it thirteen other species over a period of five years. However, a seedling Dactylorchis was recorded in 1963.
Several species lists for the plants and animals recorded in the meadow are being compiled. These include surveys of the Coleptera and other insect groups made by A. C. Warne. As yet there is little evidence that a characteristic 'wet meadow' insect fauna has specifically developed within the grazed strips; it may, however, be too early for any significant differences to have developed.

It is hoped to carry out other small experiments in the meadow. The first is designed to determine what effect cutting has on $C$. acutiformis; a start was made in August 1963 when the area of almost pure C. acutiformis, $10 \times 30 \mathrm{yd}$. (in Strip 3), was cut by hand. It is hoped to continue by cutting the same area three times annually. The second experiment is concerned with the effect of different methods of gathering the flower spikes on the survival of Dactylorchis praetermissa and $D$. incarnata.

\section{FOREST PRODUCTS RESEARCH IN CHILE}

$\mathrm{I}^{\mathrm{N}}$ $\mathrm{N}$ pursuance of the objectives set out in a conference on the "Co-ordination of Forest Products Research" in $1962^{1}$, Chilean forest products research workers met in Concepción during October 1-3, 1964, to discuss the results of their investigations.

The Conference was sponsored conjointly by the Instituto Forestal, Santiago, and the University of Concepción, and presided over by Prof. G. Pizarro, Dean of the Faculty of Engineering in the University of Concepción. Some 75 delegates from universities, Chilean and international agencies, and private industry, participated in five working groups, in which 32 papers were presented.

The timber physics group discussed nine contributions on wood anatomy and mechanical properties. G. Mittak $\left(1^{*}\right)$ and W. G. Kauman (7) demonstrated a card-sorting key for the macroscopic identification of the 30 most important Chilean woods. Independent studies of tracheid dimensions in Pinus radiata by M. Ortiz (4), and by J. Paz y R. Melo (5), agreed in showing an increase in tracheid length of the order of 100 per cent in radial direction, from pith to bark, the range being $1.60-3.90 \mathrm{~mm}$. Some discrepancies in the two sets of results pointed to the importance of proper sampling procedures. G. Julio (4) reported a similar study with Populus spp.

The mechanical strength of Pinus radiata was measured by A. Sangüesa (4) and by H. Albala (3). The means are apparently not significantly different from values for Australian-grown material, but the dispersion was considerably greater. A. Morales et al. (2) determined some minimum dimensions for the design of joints and trusses with this species, and R. Brun (I) reported correlations between mechanical properties, density and annual increment in Chilean-grown Pseudotsuga menziesii.

In wood chemistry, the accent was on pulping studies of Pinus radiata and secondary products of the same species. R. Melo and E. Madsen (5) showed that pulp produced from saw-mill waste has better physical and mechanical strength properties than that obtained from thinnings for both the sulphate and sodium sulphite pulping process. Investigations by R. Tamm and R. Melo (5) demonstrated that the nitric acid process can also bo successfully applied to the pulping of this species, a result of importance to Chile in view of the abundant nitrate deposits in the northern provinces. G. Strodthoff

* Institutions cited in the text: (1) Universidad Austral de Chile, Valdivia (2) Universidad Católica de Chile, Santiago; (3) Universidad de Chile, I.D.I.E.M. (Materials Testing Institute), Santiago; (4) Universidad de Chile, Forest Engineering School, Santiago; (5) Universidad de Coneepción;
(6) Universidad Técnica Federico Santa María, Valparaiso; (7) Instituto Forestal, Santiago: (8) U.N. Economic Commission for Latin America and Food and Agriculture Organization; (9) Compañía Manufacturera de Papeles y Cartones. and I. Salgado (9) established suitable degrees of delignification for different end-uses in relation to the bleaching of pulp of high Roe chlorine number index, and R. Melo and $J$. Dávila (5) determined the influence of temperature and composition on the rate of penetration into woodchips of sulphite cooking liquors. Liquors with sodium base were found to penetrate faster than those with calcium ion.

The content of holo- and $\alpha$-cellulose and of lignin in Pinus radiata from different provinces of Chile was found by J. Paz and María E. Ceballos (5) to average 74.05 \pm $0 \cdot 40$ per cent, $49 \cdot 15 \pm 0 \cdot 45$ per cent and $27 \cdot 81 \pm 0 \cdot 20$ per cent, respectively, with little variation with the position in the tree or geographical origin.

Secondary products of the same species were studied by G. Peteri (5), who showed that tannins extracted from the bark and polymerized in formaldehyde yield adhesives with a bond strength comparable with that of phenolformaldehyde resins, and by E. Bluhm and F. Diaz (5), who established that resin extraction from standing trees could be commercially attractive for the production of colophonium and turpentine. With stimulation by sulphuric acid, yields of up to $86 \mathrm{~g}$ per cut were obtained. 0.5 metric ton per acre could be easily obtained in a season from stands 20 years old.

Among miscellaneous investigations on the chemistry of forest products and adhesives, a noteworthy contribution by R. Ripa and M. Bórquez (6) demonstrated the presence of 13.5 per cent (Klason) lignin in the alga Durvillaea antartica by chemical means and by infra-red spectrography. The corresponding oxidation products, vanillin and syringaldehyde, were detected chromatographically. R. Ripa and Patricia Guzmán (6) reported that Pinus radiata veneer can be given a hard, glossy and water-resistant finish by impregnation with resols obtained from cresilic acid and co-polymerized with sulphate (Kraft) lignin, at $140 \mathrm{~kg} / \mathrm{cm}^{2}$ and $140^{\circ} \mathrm{C}$, with $p \mathrm{H} 6 \cdot 1$. From the bark of the same species, G. Peteri (5) obtained up to 23 per cent tannin which, when applied to leather, resulted in a product with some mechanical properties superior to leather treated with quebracho tannin. H. Schmidt (8) considered quality control in particle-board manufacture in relation to the temperature and pressure during the curing process.

The preservation group was largely concerned with durability and impregnation methods of Pinus radiata. Untreated wood was found in the laboratory to lose up to 37 per cent of weight in five months when exposed to attack by Poria vaporaria on agar base, and 7.5 per cent after 28 days attack by Reticulitermes flavipes (M. Ortiz, 4). Field trials of untreated stakes indicated a useful life of 1--2 years, whereas stakes impregnated with coal tar 